\title{
Biomedical, Sharps and General Waste Disposal in India: Potential for the Spread of Contagious Diseases and Serious Environmental Contamination
}

\author{
Vasudha Iyengar ${ }^{1,2,3, *}$, Md Rafiqul Islam ${ }^{1,2,3}$ \\ ${ }^{1}$ Goulburn Valley Health, Australia \\ ${ }^{2}$ Department of Rural Health, the University of Melbourne, Australia \\ ${ }^{3}$ School of Health and Social Development, Deakin University, Australia
}

Copyright $@ 2017$ by authors, all rights reserved. Authors agree that this article remains permanently open access under the terms of the Creative Commons Attribution License 4.0 International License

\begin{abstract}
Biomedical waste, contaminated sharps, and general garbage disposal is a huge problem in many developing countries including India. There are different waste management rules in India for managing different kinds of waste. These rules were revised in 2016. However, the application and practice of handling different kinds of waste as per the rules are still inadequate. Mixing general and medical waste together for disposal accentuates the situation, especially as a significant threat for sharp or needle-stick injuries. India's waste production is huge and traditional management of these mixed and contaminated wastes is a serious public and population health issue. It is also creating massive environmental concerns. Adequate hospital or biomedical waste management policy enforcement, strong public health promotional research and media campaigns, safe practice and personal hygiene education via social and mass media may alleviate the spread of serious contagious diseases. India has a high social media utilization and excellent wireless and broadband coverage. These can be used as an educational or health promotional tools to keep the public away from contagious diseases. In addition to enforcement of practicing waste management rules or guidelines, a global public health campaign on many levels is urgently required to ensure India is able to contain potential pandemics of blood borne conditions due to poor medical waste disposal practices.
\end{abstract}

Keywords Biomedical Waste, General Waste, India

\section{Introduction}

The inadequate contaminated waste collection, transport, treatment and disposal in India are causing major environmental challenges [1]. With 1.2 billion people plus and a growing urban population, India's medical, sharps and hospital garbage disposal, unsafe public space hygiene, and general waste and sewerage management problem is vast and incomprehensibly huge. Coping with this is highly challenging, multifaceted, and a sociological and population based issue impacting in a major way on global and Indian public health [1]. Despite having revised waste management rules or guidelines for different kinds of waste in India (GSR Codes 320E, 338E, 343E, 317E, 395E and S.O.1357 E, 2016), the practice and handling of different waste management remain inappropriate. A similar scenario may be prevailing in most Southeast Asian countries. However, evidence of the problem is visible in India due to its scale and size within Southeast Asia; it is enhanced by India's lack of urban and rural planning for general and contaminated garbage and medical waste disposal.

Refuse, composting garbage and open air rubbish can be seen on many street corners. It is also visible in the midst of the Indian hinterlands. The trash festers; feeding stray animals and sustaining rabid dogs. The exposed trash provides a hunting ground for scavenging street children. These further create a fertile landscape for a plethora of happy, noxious insects and mosquito colonies that may result in easily contagious, highly undesirable public health issues and diseases.

Some cities and neighborhoods are better at sorting this problem out than others. Some suburbs have solved much of this problem by specifically employing wet and dry garbage collection services and enforcing local community regulations especially related to sharps and medical waste disposal. Usually, these areas are well heeled 'societies or housing colonies' as such neighborhoods are known in Indian cities and towns. But the numbers of people who have resolved this problem with their own ingenuity and their own financial means are few. It is much more common to see exposed, mixed garbage in urban and rural areas not dealt with in a rational, safe and hygienic manner. 
Many Indians believe that the governments of state and central jurisdictions have put in limited effort to enforce the safety policies for urban garbage and noxious waste management. The Indian public may now believe with some justification that effective public health policy is exceptionally difficult to manage and implement as the garbage and recyclable waste disposal problem has escalated to a potentially unmanageable stage.

Additionally, handling and managing plastic contaminated waste is a serious global environmental problem. However, the magnitude of this public health problem in India is huge. Plastic containers, the ubiquitous commercial plastic water bottle, glittery wrappers for chocolates and snacks litter every part of India's main roads, back roads, suburban areas, gutters, and side streets. There is also the popularly held belief, that this waste disposal problem is either the government, corporation, local council or someone else's matter to handle; the public believes that to collect and dispose of this discarded plastic is not their responsibility. Amongst these plastic wastes, 'plastic disposable syringe with or without needle' is another public health concern. Most of these plastic syringes tend to be thrown out with general public waste; the factor of concern is that these syringes are contaminated with body fluids.

\section{Methods}

This personal opinion article is derived from anecdotal and life experience along with the review of print and electronic media releases during and after the Delhi Commonwealth Games in 2010. We also conducted a literature review for freely available articles in PubMed to date. We used the key terms "Waste disposal" And "India", or "Biomedical Waste Disposal" And "India" and limited the search for "Free Full-Text Articles" in past five years between 2012 and 2017. We found a total of 61 free full-text articles that cover both biomedical and general waste disposals along with public health and environmental problems. The same search strategy was utilised for abstracts and without limiting time and we found 1296 online abstracts available in PubMed. Only a few relevant abstracts were selected and full texts were collected from our own institutional library.

\section{Findings}

During 2010 Delhi Commonwealth games, the soiled toilets and rubble within the athlete's quarters were flashed to millions of television viewers worldwide, accompanied by varying expert commentaries on how India could not get its hygiene, sanitation, and development act together. However, the government has picked up on this situation, using popular television media to advertise their sorrow at the accumulating garbage in India's public spaces. They also began a media campaign for public health literacy in matters of personal hygiene. This is a positive step and a careful media related strategy taken by the Central Indian government. The television as an educational and policy dissemination medium is widely acknowledged in India as being a very effective tool. Television can easily influence the Indian public and especially the child populace. Indian Media attempted to showcase Prime Minister Modi and his personal efforts to sweep his own residential street clean, very much in line with the self-sufficient 'Gandhian' belief system.

The most important problem area covers the means by which Indian medical waste is disposed of. The area of problems with contaminated medical and drug user sharps is also very pertinent to the modern situation in India. The range of medical waste generation in India is between 0.5 and $2.0 \mathrm{~kg}$ bed-1 day- 1 . Annual Indian estimation of total medical waste is about 0.33 million tons. Among the hospital waste, food, bandage, linen and other infectious waste constitutes $70-80 \%$, while plastics, disposable syringes and glass constitute $7-10 \%, 0.3-0.5 \%$, 3-5\%, respectively. This waste is generally collected in a mixed form, transported and disposed of along with municipal solid wastes [2, 3]. Despite hazardous wastes, indiscriminate disposal of solid medical wastes continues to occur posing environmental and public health consequences [4]. However, many registered hospitals honor their commitment to safe and effective, infective hazard and waste disposal systems.

Children on the street ferreting in these hazardous sharps' infested dump sites for food is a common sight. It's saddening to think of the often inadvertent contaminated needle stick injuries these children sustain on these sharps infested waste sites. An Indian study indicates $30-35 \%$ of the health care personnel in a large hospital lacked knowledge on bio medical waste management; this ignorance further accentuates a massive public health problem. Occupational needle-stick injury prevention strategies in India are lacking in policy, enforcement or surveillance systems.

Another big concern is how approximately 320 million Indians diagnosed with diabetes and requiring injected insulin treatments [7] dispose of their insulin dispensing syringe and needles. How do 1.1 million injecting drug users (IDUs) in India [8] dispose of their needles? However, a study reported that sharp disposal into household waste bins by the diabetes patients in India is $84.1 \%$ [9] and there is no data on the prevalence of sharp injuries from this household waste.

\section{Discussion}

General and biomedical waste disposal and handling remain a major concern in India; this may be true for other types of waste management too. Their consequences to public health and environment are yet to be fully understood. There is a lack of enforcement of relevant rules and guidelines as well. There is also a variable ineffective health campaign in the media. 
Not that any major investigation into this matter can come up with a study of serious intent as a valid example. The inadequacy of government or a private sector planning for infrastructure and equipment development is a problem especially related to the provision of sharps disposal facilities in public spaces.

Another critical body fluid waste is the soiled menstrual product. There is no specified method of disposing of soiled sanitary hygienic products or blood soaked surgical waste in this nation. Often, these products lie out in the open in the garbage. They just get thrown out without a cover into "normal garbage." The producers of tampons and sanitary hygiene products; namely very large multinational pharmaceutical companies should care that India is being littered with these soiled, sanitary and surgical waste products and that many of these are encased in non-recyclable plastic. These companies should develop a conscience to world public health in this era of mass human flow, travel and migration. Some attempts at educating the public about the careful disposal of soiled menstrual waste are occurring but not enough. Much effort and expense though is expended by the producers in advertising their sanitary feminine hygiene products as 'hygienic' and 'user-friendly' to approximately 1200 million people in India.

Global health and policy making organizations would be well advised to work towards the containment of the enormous problems of Indian street children who may infect many with HIV or hepatitis from this unmanaged garbage situation. There is a lot to do towards resolving this hazardous nationwide sharps situation. Is it being tackled robustly enough or with delicate gloves on for fear of offending political and religious sensibilities? Very real and escalating global pandemic risks exist due to the hidden spread of notifiable disease in this situation.

Street children are the very poorest people in India; they seem to have sadly, utterly dispensable lives. Strong health promotional campaigns to protect these vulnerable children from the consequences of their foraging in the toxic garbage are required. Several other serious adverse outcomes may be related to improperly managed medical and general waste. For example, in 2010, the universally antibiotic-resistant and thus potentially fatal strain of the E Coli bacterium surfaced from India, named the Delhi strain. Reports in scientific literature as recent as September 2016 are emerging of Indian super bugs, dangerous and antibiotic-resistant bacteria that only the fiercest and most expensive antibiotics can control at this present time [10]. Normal run-of-the-mill antibiotics are useless in the face of these super bugs.

Much of the responsibility for this modern social and environmental issue lies with secondary and tertiary education in India. The education received at Indian secondary schools and medical institutions are often not exactly well rounded. It's a literacy campaign at best. The Indian education school and University system are more about rote learning, a limited and often poorly written syllabus, poorly selected texts completely out of synch with India's sociological and public health needs. Besides, children are forced into getting adequate examination results rather complete a holistic 'life skills' based education. To teach Indian students to maintain a clean and safe environment has passed the Indian education system by in these past few decades. When a literate young Indian does not know how to safely dispose of their own soiled refuse, medical and household contaminated waste or how to hygienically manage soiled menstrual waste and sharps, then a productive life education has not occurred.

The inclusion of a compulsory health and hygiene education syllabus in all public and private schools and at primary, secondary and tertiary educational levels could alleviate the problem. Alongside every degree or diploma, it should be compulsory in India to pass a 'safe hygiene and sharps management module' to achieve the degree or diploma. This compulsory repetitive education module might rapidly minimize such medical waste disposal and contamination problems in public health give or take a decade; given that diabetes is a condition that will be diagnosed in many millions of people in India by 2030 [7]. Simple, inexpensive, well-managed community garbage handling and management systems that can be handled at a local level need serious promotion in India. They can, along with strictly followed government guidelines to manage medical and general waste disposals by all people, be an effective strategy to combat this enormous public health and environmental problem. Also, it is the time to widely implement the alternate use of solid waste for energy production. That program seems to have petered out and could be revived to suit modern needs. Additionally, a comprehensive, repetitive public health promotional campaign through mass media would work best in this setting.

\section{Conclusions and Recommendation}

The Central Government and Not for Profit agencies should, in our view, be committed to the management and enforcement of existing laws and policies for public health and safety. The agencies need to consider it their dedicated goal to innovate appropriate citizen licenses and cards to manage general, biomedical and sharps waste disposal by all people including people injecting medications or drugs. The United Nation (UN) agencies require taking a serious interest in this space to influence and negotiate the achievement of a 'global public pandemic prevention and hygiene safety' Indian program. We strongly advocate a well-orchestrated and long term global health and safety strategy would preserve the miracle of life for many millions of poor children in India and millions of other vulnerable adults.

Linking the completion of primary sanitation and hygiene education to the obtaining of the 'Aadhar' card, (a national numerical citizen identifier and license enabler) may also 
work as an implementation policy to educate and enforce healthful living with clean sanitation behavior. This would work in the regional and remote areas too where literacy may be problematic.

An additional 'Injecting diabetes person's card' could be made compulsory also to ensure those patients injecting for diabetes management are enforced to carry such a card to secure their safe management of sharps. Having to apply for, maintain and having to renew the 'injecting diabetic person's compulsory card' after such a diagnosis should be mandatory. Further linking the card's successful annual or two yearly renewals to safe sharps waste disposal education programs would, in our view be a successful initiative. Intermittent license examinations of the patient's sharps disposal processes could save many lives as a nation- wide public health policy. The government may have to invest in public space sharps disposal systems for such policies to work.

These initiatives are challenging, religiously sensitive, sociologically difficult and epidemiologically strenuous work. They may be initially expensive. Nevertheless, the cumulative positive effects on overall global population health in a few years could be a lot less expensive with the implementation of these policies. These sorts of multinational, non-politically motivated and sociologically productive public health and safety movements could create an efficient mechanism for building a safer and healthier Indian nation. These movements would also help preserve the life-saving miracle of antibiotics, antivirals, antifungal and antiretroviral medications for the contagious diseases that afflict the poorest in any country.

\section{Competing Interest}

The authors declare no competing interest.

\section{Authors Contribution}

VI conceptualizes the idea and wrote the article. MRI: reviewed literature and wrote the article

\section{REFERENCES}

[1] Kumar, S., et al., Challenges and opportunities associated with waste management in India. R Soc Open Sci, 2017. 4(3): p. 160764.

[2] Patil, A.D. and A.V. Shekdar, Health-care waste management in India. J Environ Manage, 2001. 63(2): p. 211-20.

[3] Boss, U.J., et al., Biomedical waste generation in Puducherry Government General Hospital and its management implications. J Environ Health, 2009. 71(9): p. 54-8.

[4] Misra, V., and S.D. Pandey, Hazardous waste, impact on health and environment for the development of better waste management strategies in future in India. Environ Int, 2005. 31(3): p. 417-31.

[5] Rao, P.H., Report: Hospital waste management--awareness and practices: a study of three states in India. Waste Manag Res, 2008. 26(3): p. 297-303.

[6] Pandey, A., et al., Bio-Medical Waste Managment in a Tertiary Care Hospital: An Overview. J Clin Diagn Res, 2016. 10(11): p. DC01-DC03.

[7] Kaveeshwar, S.A. and J. Cornwall, The current state of diabetes mellitus in India. Australas Med J, 2014. 7(1): p. 45-8.

[8] C Aceijas, et al., Estimates of injecting drug users at the national and local level in developing and transitional countries, and gender and age distribution. Sex Transm Infect, 2006. 82(4): p. 344.

[9] Anindo Majumdar, et al., Improper sharp disposal practices among diabetes patients in home care settings: Need for concern? Indian J Endocrinol Metab, 2015. 19(3): p. 420-425.

[10] Amit Ranjan, et al., Molecular epidemiology and genome dynamics of New Delhi Metallo-beta-lactamase (NDM) producing extraintestinal pathogenic E. coli (ExPEC) strains from India. Antimicrobial agents and chemotherapy, American Society for Microbiology, 2016. 61(6) 